NASA/TP-2004-212694

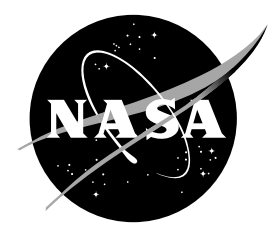

\title{
Fully Suspended, Five-Axis, Three-Magnetic- Bearing Dynamic Spin Rig With Forced Excitation
}

Carlos R. Morrison, Andrew Provenza, and Anatole Kurkov

Glenn Research Center, Cleveland, Ohio

Gerald Montague

U.S. Army Research Laboratory, Glenn Research Center, Cleveland, Ohio

Kirsten Duffy

University of Toledo, Toledo, Ohio

Oral Mehmed and Dexter Johnson

Glenn Research Center, Cleveland, Ohio

Ralph Jansen

University of Toledo, Toledo, Ohio 
Since its founding, NASA has been dedicated to the advancement of aeronautics and space science. The NASA Scientific and Technical Information (STI) Program Office plays a key part in helping NASA maintain this important role.

The NASA STI Program Office is operated by Langley Research Center, the Lead Center for NASA's scientific and technical information. The NASA STI Program Office provides access to the NASA STI Database, the largest collection of aeronautical and space science STI in the world. The Program Office is also NASA's institutional mechanism for disseminating the results of its research and development activities. These results are published by NASA in the NASA STI Report Series, which includes the following report types:

- $\quad$ TECHNICAL PUBLICATION. Reports of completed research or a major significant phase of research that present the results of NASA programs and include extensive data or theoretical analysis. Includes compilations of significant scientific and technical data and information deemed to be of continuing reference value. NASA's counterpart of peerreviewed formal professional papers but has less stringent limitations on manuscript length and extent of graphic presentations.

- TECHNICAL MEMORANDUM. Scientific and technical findings that are preliminary or of specialized interest, e.g., quick release reports, working papers, and bibliographies that contain minimal annotation. Does not contain extensive analysis.

- CONTRACTOR REPORT. Scientific and technical findings by NASA-sponsored contractors and grantees.
- CONFERENCE PUBLICATION. Collected papers from scientific and technical conferences, symposia, seminars, or other meetings sponsored or cosponsored by NASA.

- SPECIAL PUBLICATION. Scientific, technical, or historical information from NASA programs, projects, and missions, often concerned with subjects having substantial public interest.

- TECHNICAL TRANSLATION. Englishlanguage translations of foreign scientific and technical material pertinent to NASA's mission.

Specialized services that complement the STI Program Office's diverse offerings include creating custom thesauri, building customized databases, organizing and publishing research results ... even providing videos.

For more information about the NASA STI Program Office, see the following:

- Access the NASA STI Program Home Page at http://www.sti.nasa.gov

- E-mail your question via the Internet to help@sti.nasa.gov

- Fax your question to the NASA Access Help Desk at 301-621-0134

- Telephone the NASA Access Help Desk at 301-621-0390

- Write to:

NASA Access Help Desk

NASA Center for AeroSpace Information 7121 Standard Drive

Hanover, MD 21076 
NASA/TP—2004-212694

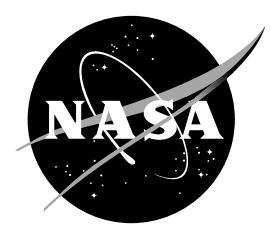

\section{Fully Suspended, Five-Axis, Three-Magnetic- Bearing Dynamic Spin Rig With Forced Excitation}

Carlos R. Morrison, Andrew Provenza, and Anatole Kurkov

Glenn Research Center, Cleveland, Ohio

Gerald Montague

U.S. Army Research Laboratory, Glenn Research Center, Cleveland, Ohio

Kirsten Duffy

University of Toledo, Toledo, Ohio

Oral Mehmed and Dexter Johnson

Glenn Research Center, Cleveland, Ohio

Ralph Jansen

University of Toledo, Toledo, Ohio

National Aeronautics and

Space Administration

Glenn Research Center 


\section{Acknowledgments}

The authors would like to express their appreciation to Dr. Gerald Brown for his assistance in getting the rig to its final operational status. We thank Mr. John Poles for implementing the extensive and intricate electrical wiring in the rig, Mr. Joe Wisniewski for his assistance with the rig's electronics wiring, and Mr. Jeffrey Hamman for his mechanical ability in assembling the rig. In addition, we thank Mr. Timothy Czaruk for designing the Lab View Interface used to monitor the control currents in the coils and David Wong for implementing the angular sweep logic block into the latest version of the code.

This work was sponsored by the Low Emissions Alternative

Power Project of the Vehicle Systems Program at the NASA Glenn Research Center.

Available from

NASA Center for Aerospace Information 7121 Standard Drive

Hanover, MD 21076
National Technical Information Service 5285 Port Royal Road Springfield, VA 22100 


\title{
Fully Suspended, Five-Axis, Three-Magnetic-Bearing Dynamic Spin Rig With Forced Excitation
}

\author{
Carlos R. Morrison, Andrew Provenza, and Anatole Kurkov \\ National Aeronautics and Space Administration \\ Glenn Research Center \\ Cleveland, Ohio 44135 \\ Gerald Montague \\ U.S. Army Research Laboratory \\ Glenn Research Center \\ Cleveland, Ohio 44135 \\ Kirsten Duffy \\ University of Toledo \\ Toledo, Ohio 43606 \\ Oral Mehmed and Dexter Johnson \\ National Aeronautics and Space Administration \\ Glenn Research Center \\ Cleveland, Ohio 44135 \\ Ralph Jansen \\ University of Toledo \\ Toledo, Ohio 43606
}

\section{Summary}

The Five-Axis, Three-Magnetic-Bearing Dynamic Spin Rig, a significant advancement in the Dynamic Spin Rig (DSR), is used to perform vibration tests of turbomachinery blades and components under rotating and nonrotating conditions in a vacuum. The rig has as its critical components three magnetic bearings: two heteropolar radial active magnetic bearings and a magnetic thrust bearing. The bearing configuration allows full vertical rotor magnetic suspension along with a feed-forward control feature, which will enable the excitation of various natural blade modes in bladed disk test articles. The theoretical, mechanical, electrical, and electronic aspects of the rig are discussed. Also presented are the forced-excitation results of a fully levitated, rotating and nonrotating, unbladed rotor and a fully levitated, rotating and nonrotating, bladed rotor in which a pair of blades was arranged $180^{\circ}$ apart from each other. These tests include the "bounce" mode excitation of the rotor in which the rotor was excited at the blade natural frequency of $144 \mathrm{~Hz}$. The rotor natural mode frequency of $355 \mathrm{~Hz}$ was discerned from the plot of acceleration versus frequency. For nonrotating blades, a blade-tip excitation amplitude of approximately $100 \mathrm{~g} / \mathrm{A}$ was achieved at the first-bending critical $(\sim 144 \mathrm{~Hz})$ and at the first-torsional and second-bending blade modes. A blade-tip displacement of 70 mils was achieved at the first-bending critical by exciting the blades at a forced-excitation phase angle of $90^{\circ}$ relative to the vertical plane containing the blades while simultaneously rotating the shaft at $3000 \mathrm{rpm}$.

\section{Symbols}

A cross section

c constant defined in eq. (A9)

$B \quad$ magnetic flux density 
$F \quad$ net controlling force on rotor

$f \quad$ force on rotor due to one pole

$g \quad$ acceleration due to gravity $\left(9.8 \mathrm{~m} / \mathrm{s}^{2}\right)$

H magnetic field

$i \quad$ current in coil

K control gain

stiffness

$k_{e q}$ rigid rotor equivalent spring constant

$l_{f e} \quad$ mean length of magnetic displacement

$m_{e q}$ rigid rotor equivalent lumped mass

$n \quad$ number of turns in coil

$s \quad$ air gap spacing

$\dot{s}_{d e} \quad$ linear velocity of shaft

$\ddot{s}_{d e} \quad$ linear acceleration of shaft

$V \quad$ volume

$W \quad$ magnetic energy

$\Phi \quad$ magnetic flux

$\mu \quad$ permeability

$\mu_{0} \quad$ permeability of free space

$\omega \quad$ excitation frequency

Subscripts:

$A_{a} \quad$ through air gap cross section

$A_{f e} \quad$ through iron cross section

a air gap between stator and rotor $b \quad$ bias

c control

d derivative

de deviation from nominal gap distance between stator and rotor

eq equivalent

ex excitation

fe iron

$i \quad$ current

$l \quad$ linearized

$p \quad$ proportional

$r \quad$ relative

$s \quad$ position

0 nominal

\section{Introduction}

Vibration is a bane in turbomachinery and is responsible for more than 40 percent of the blade failures in gas turbines (refs. 1 to 3). Blade vibration in jet engines is responsible for noise and blade fatigue. Fatigue poses a safety risk; therefore, it is important to devise mechanisms and techniques for studying vibration and its effect on turbomachinery components. The NASA Glenn Research Center has been working on structural vibration and controls in turbomachinery and has built the Dynamic Spin Rig (DSR, ref. 4) to assist in this research (fig. 1).

The DSR employed two voice-coil-type linear electromagnetic shakers to apply oscillatory axial forces to the rotor and test blades through a thrust bearing. A subsequent upgrade of the DSR (ref. 5) incorporated a single heteropolar radial active magnetic bearing, which allows magnetic excitation and two-axis radial suspension of the rotor. The upgraded DSR (fig. 2) supported a vertical rotor by 


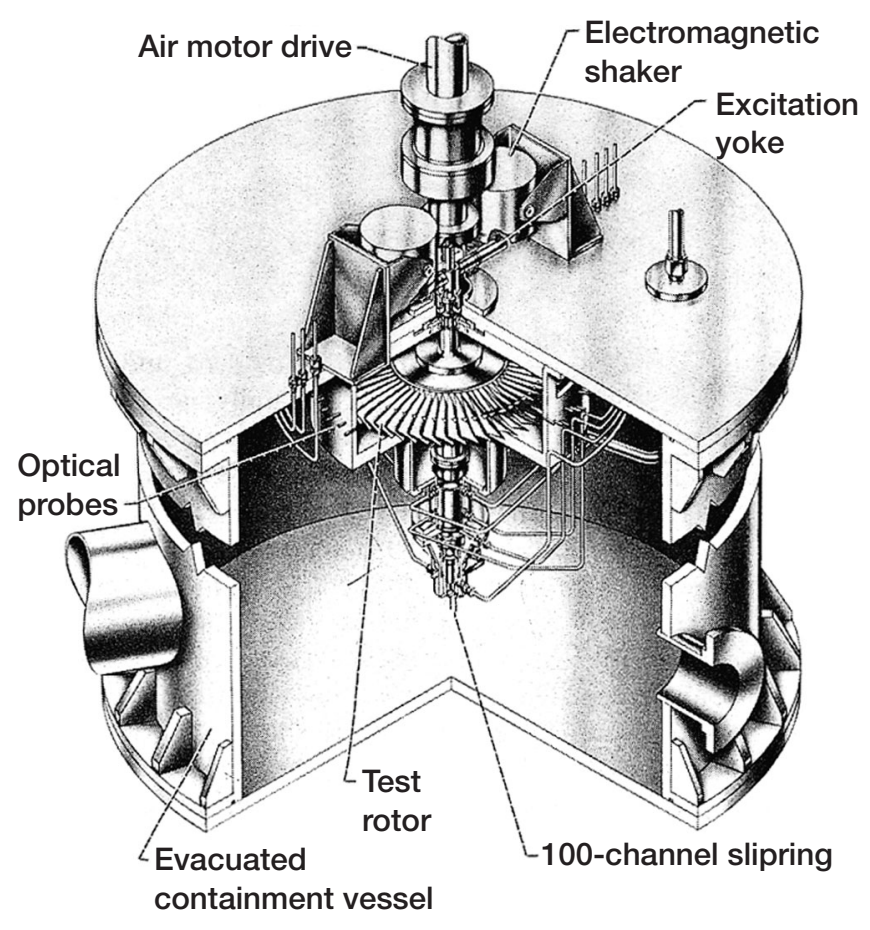

Figure 1.-Dynamic Spin Rig.

employing a conventional radial ball bearing at the upper end and a radial magnetic bearing at the lower end.

The rig shown in figure 2 was used to perform vibration tests of turbomachinery blades and components under spinning conditions in a vacuum. However, the ball bearing imposed limitations on the maximum rotational speed of the rotor $(18000 \mathrm{rpm})$ and on the test duration at lower speeds due to frictional heating. These operational limitations adversely affected the nature and type of research that could be conducted on test articles. Indeed, it was the desire to surpass the rotational speed and operational duration ceilings and to have the enhanced excitation capabilities that gave rise (ref. 5) to the late 1990's notion of total magnetic suspension for the DSR.

The Five-Axis, Three-Magnetic-Bearing Dynamic Spin Rig is the progeny of the total rotor suspension goal and represents a significant advancement beyond the capabilities of the previous rigs. This advanced rig (figs. 3 and 4) is discussed in detail in this report and consists of a magnetic thrust bearing, a magnetic radial upper bearing, and a magnetic radial lower bearing. Both radial bearings are heteropolar. Simultaneously energizing the bearings under closed-loop control (refs. 6 and 7) effects full levitation of the rotor, making it possible to achieve higher rotational speeds (in excess of $18000 \mathrm{rpm}$ ). The upper

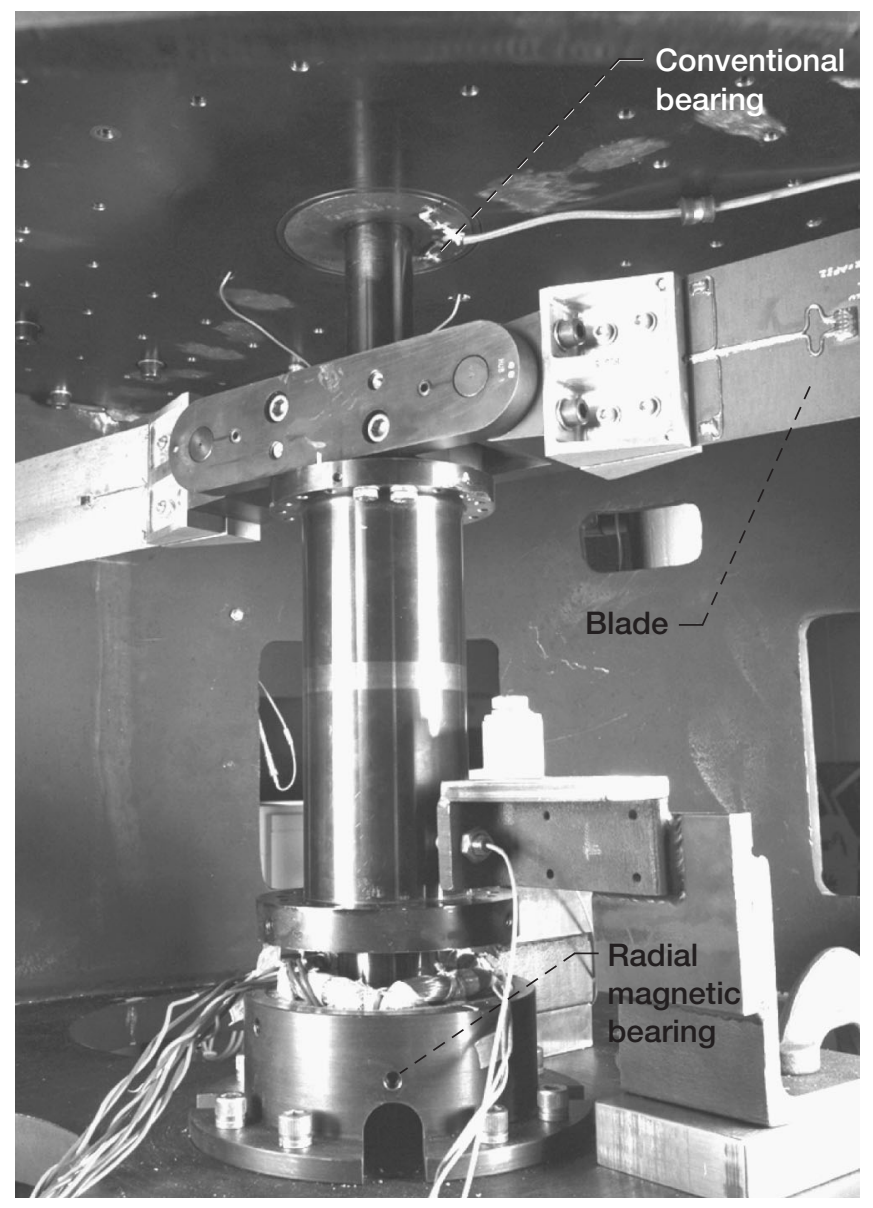

Figure 2.-Upgraded Dynamic Spin Rig showing conventional upper bearing and lower radial magnetic bearing.

rotational speeds are now limited mainly by containment issues and stresses in the test articles. The higher rotational speed is a critical element in high-cycle-fatigue research projects pertaining to the damping and mistuning of bladed disks. This rig design should also allow higher excitation amplitudes (by virtue of full rotor suspension, which permits larger rotor translation and tilt displacements) than were achievable with the previous rig configuration.

This report presents the basic theory and design parameters of the new rig and also discusses the excitation data gleaned from tests involving (a) an unbladed, nonrotating and rotating (10 $000 \mathrm{rpm}$ ) rotor and (b) a bladed rotor that was excited in the nonrotating manner and then subsequently spun at $3000 \mathrm{rpm}$. The next section discusses the requisite computer hardware specification for successful rig operation. The reader is directed to appendixes $\mathrm{A}$ and $\mathrm{B}$ for additional information related to the theoretical aspect of the rig. 


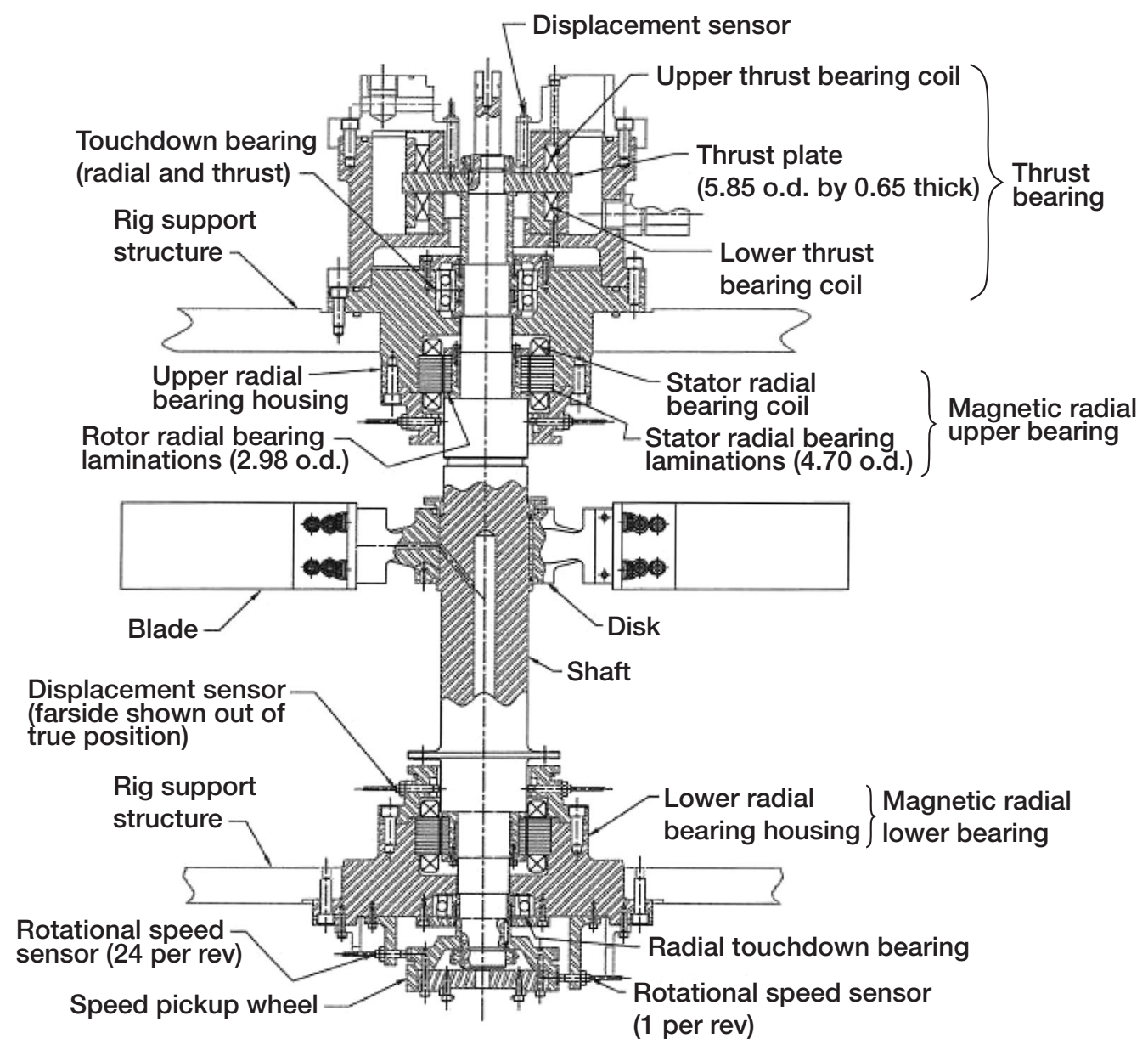

Figure 3.-Engineering schematic of five-axis ensemble. (All dimensions are in inches.)

\section{Computer Hardware}

Experience has shown that robust control of the fiveaxis-rig rotor at all operating speeds requires a control code loop time at or below $100 \mu$ s. To achieve this level of performance, a $400-\mathrm{MHz}$ Pentium II processor was used to effect a code loop time of $50 \mu \mathrm{s}$. There are 8 input board channels ( 5 proximeter sensors, one 24-per-revolution, one 1-per-revolution, 1 external signal import) and 11 output board channels. Of these, four are used for the lower bearing, four for the upper bearing, and two for the thrust bearing. The remaining channel is used for outputting the optional excitation signal (generated within the code) to an oscilloscope. The bearings and bearing components are discussed in the next section. Reference 6 provides additional hardware information and a detailed explanation of the 1-per-revolution signal logic.

\section{Bearing Components and Rig Support Structure}

The five-axis rig contains three magnetic bearings: a thrust bearing, a radial upper bearing, and a radial lower bearing. The thrust bearing has 2 thrust coils, each of which has 225 turns of 19-gauge copper wire. Each radial stator has 4 coils, each having 156 turns of 2- by 24 -gauge copper wire. Figure 5 shows the upper and lower radial stators; figure 6 , the axial view of a radial magnetic-bearing stator lamination showing four three-sectional pole elements; figure 7 , the actual rotor hanging from the rig support structure; figure 8 , the top portion of the rotor where the thrust bearing is affixed. Figure 9 illustrates the thrust plate and the thrust coils, and figure 10 depicts the fully assembled rig supported by the test cell service tripod. In high-speed experiments, the rig is operated in the vacuum chamber shown in figure 11 . 


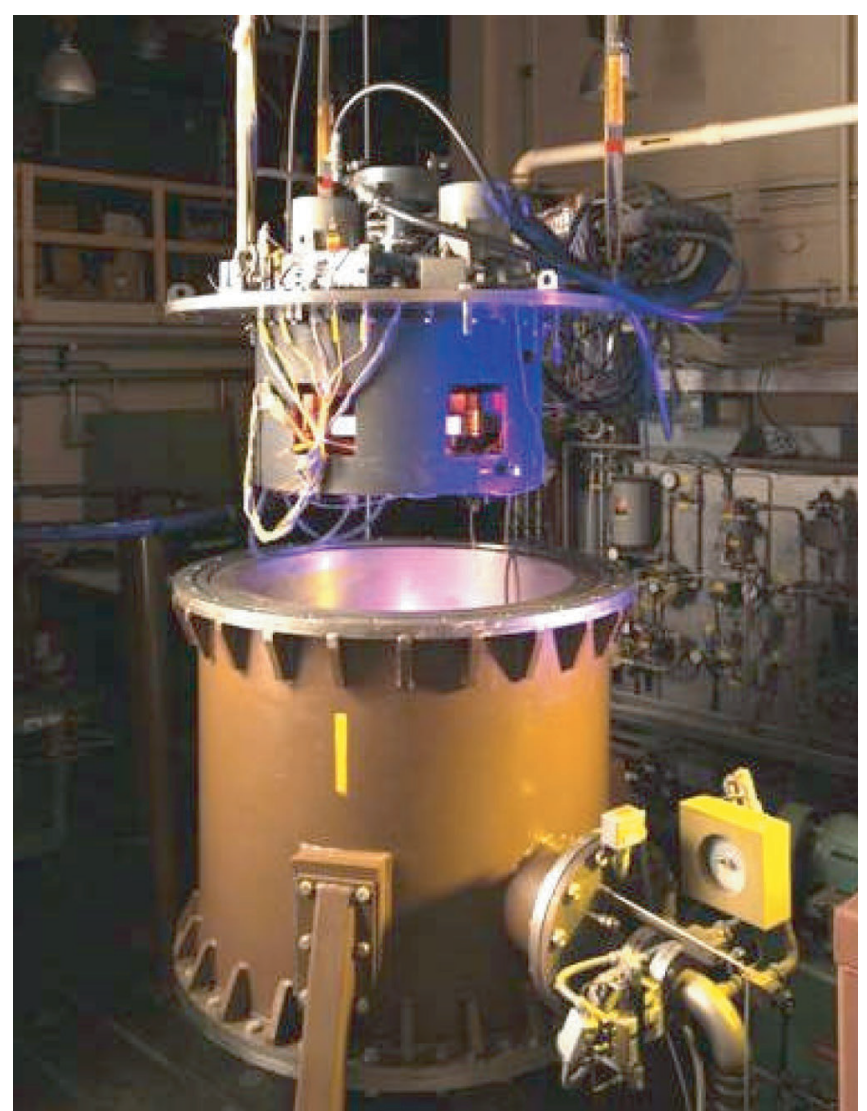

Figure 4.-Five-axis rig in its current configuration.

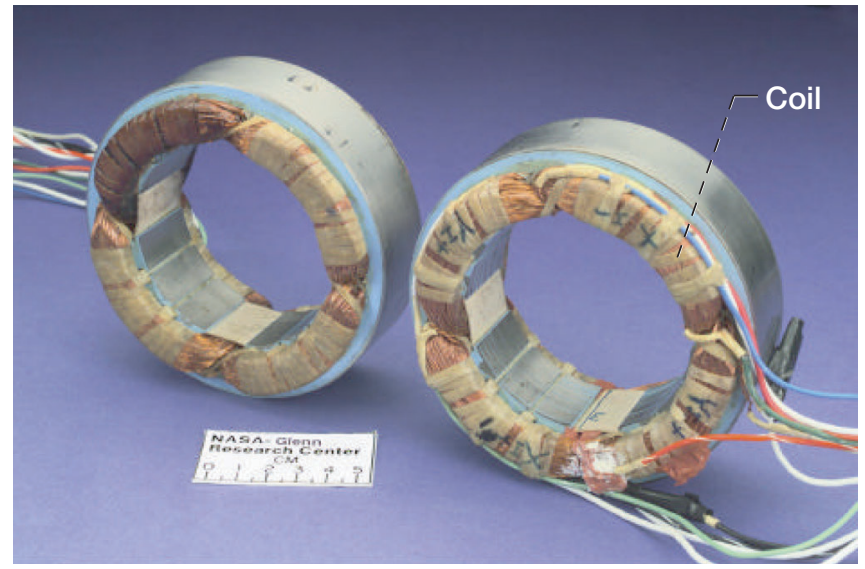

Figure 5.-U Upper and lower radial stators.

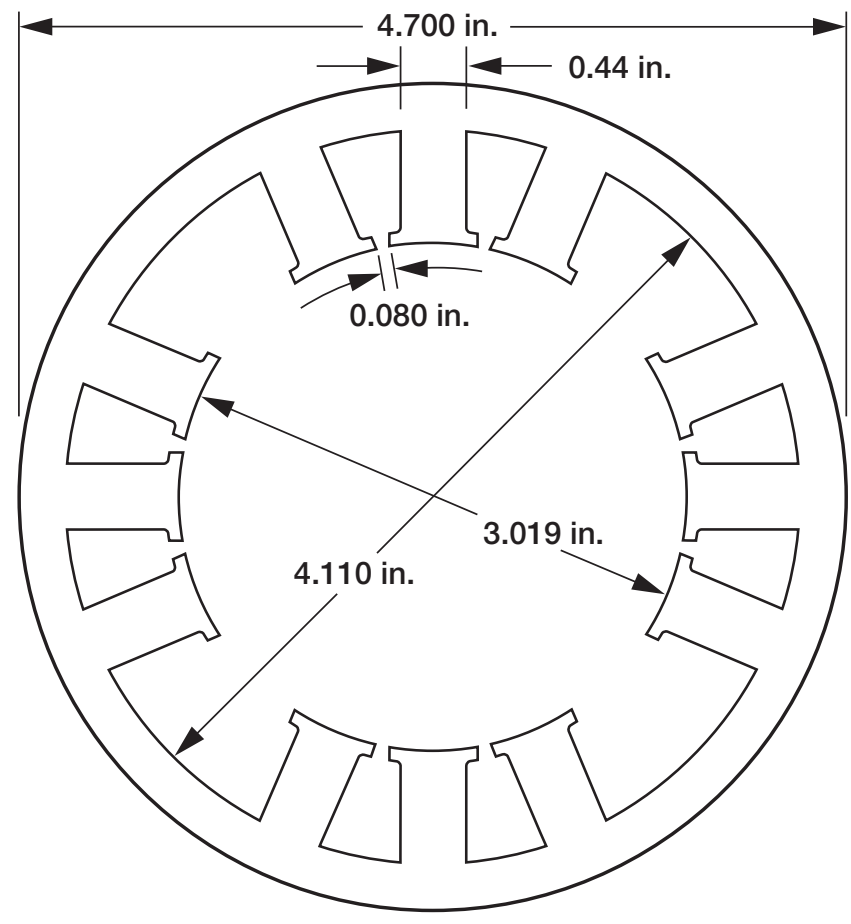

Figure 6.-Axial view of radial bearing stator lamination.

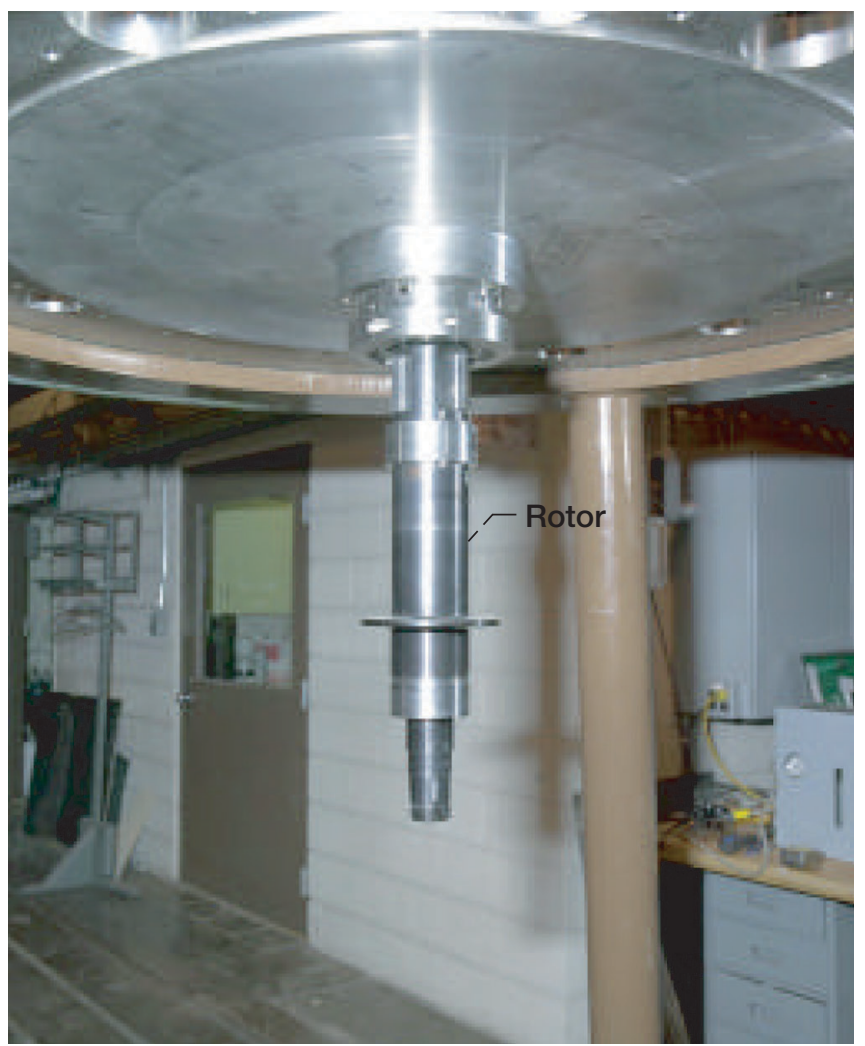

Figure 7.-Rotor hanging from rig support structure. 


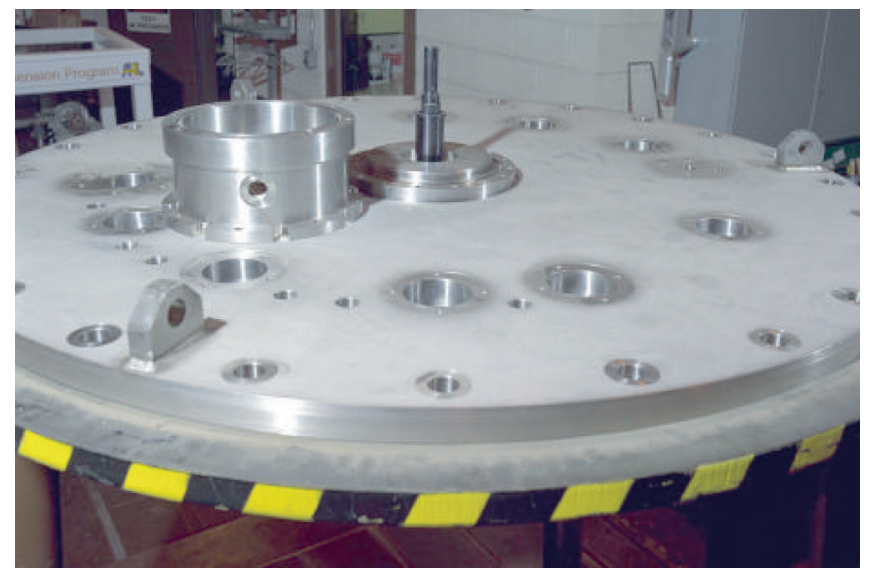

Figure 8.-Top view of rotor without thrust bearing assembly.

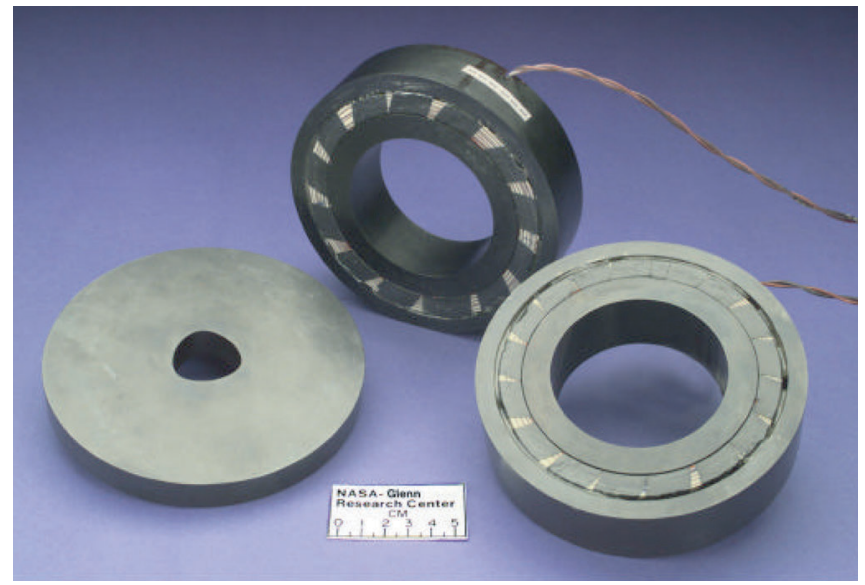

Figure 9.-Thrust plate and thrust coils.

It should be noted that the multisectional design of each of the four poles in the radial stator (fig. 6) is dispensable. These radial laminations were adapted from a motor project as a cost-cutting measure. The unusual bore geometry in the thrust plate (known as a three-point polygon, fig. 9) obviates the need for a shrink fit onto the rotor, thus minimizing radial and tangential stresses between the plate and rotor. The top portion of the rotor, having a similar geometry but a slightly smaller dimension, fits snugly into the bore.

A commercially available power amplifier (coupled with the aforementioned computer controller) is used to energize and control each coil in the bearings discussed above. Each coil is driven by a pulse-width-modulated (PWM) amplifier that can output up to $170 \mathrm{~V}$ at $15 \mathrm{~A}$ continuously and $30 \mathrm{~A}$ for short durations. The amplifiers and the tuning procedure are discussed next.

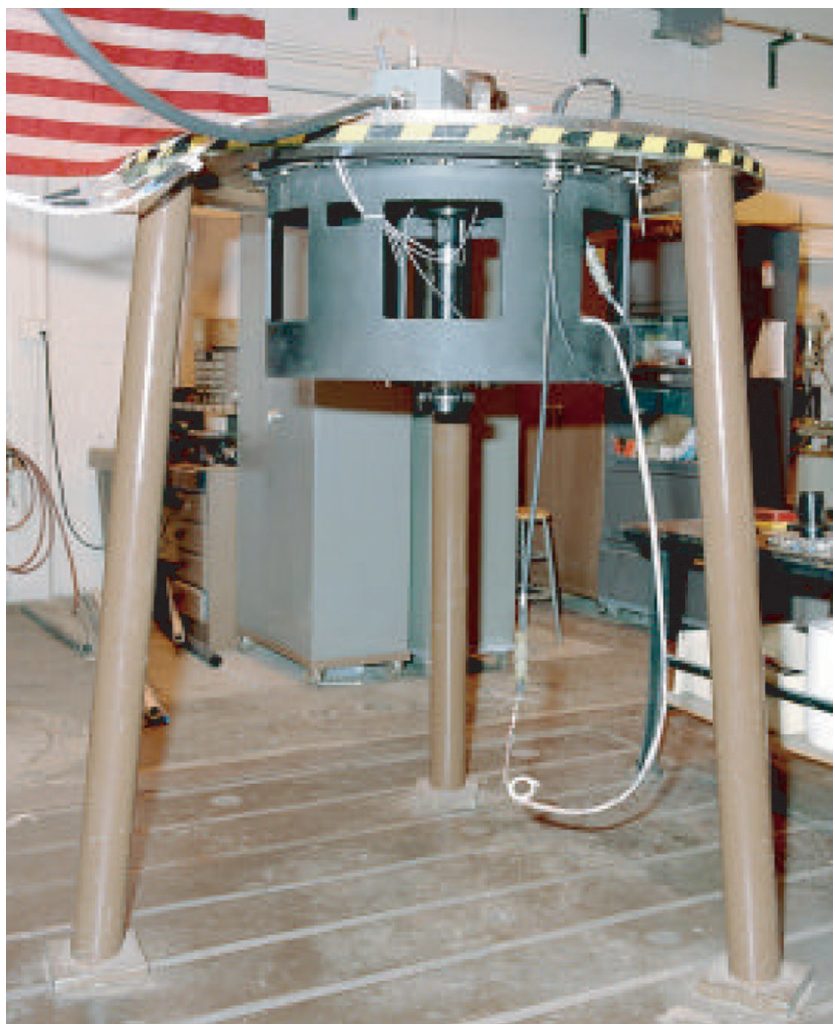

Figure 10.-Fully assembled rig mounted on test cell service tripod.

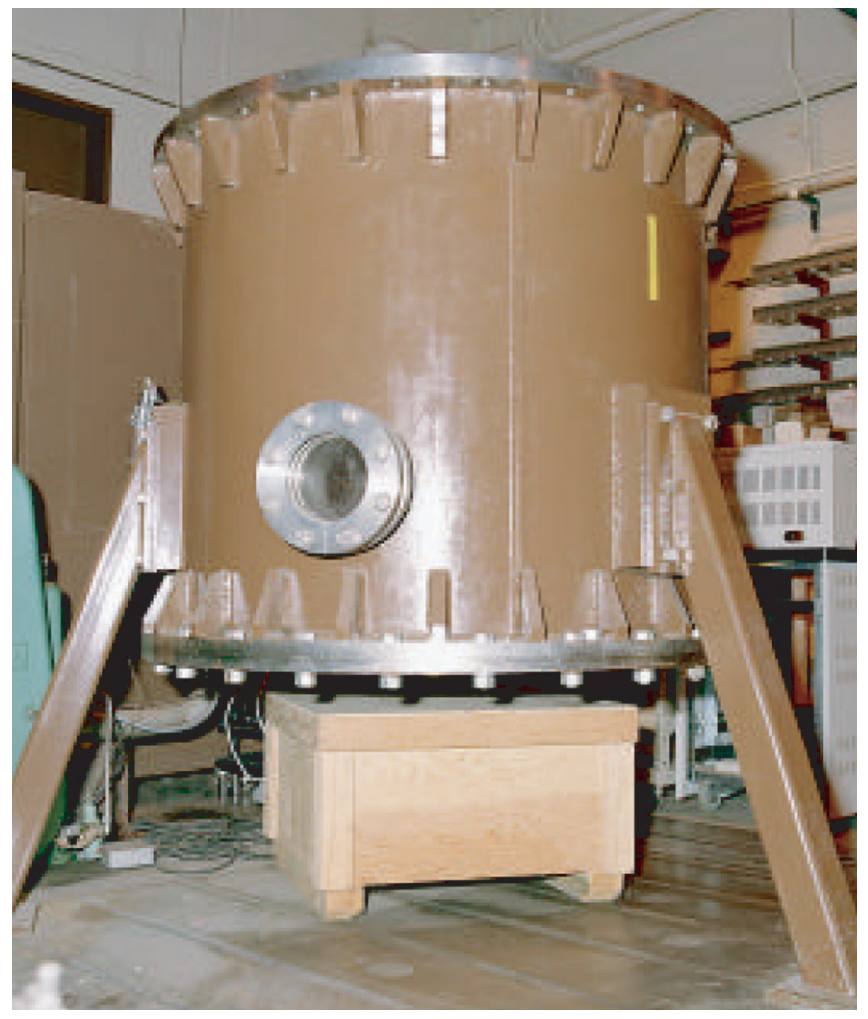

Figure 11.-Vacuum chamber. 


\section{Power Amplifier Tuning}

For stability and maximum bandwidth, each amplifiercoil pair has to be matched. Prior to this task, tests were performed to detect wire-to-wire or coil-to-stator shorts. These tests include resistance and inductance measurements, continuity, and megger wire insulation tests. A lowamplitude dc signal was applied to the actuator coils, and the flux polarity was determined by using a thin Hall-effect probe inserted in the air gap between the center of the pole and the rotor. Knowledge of the flux direction is necessary for the apposite design of the control code voltage output. These and some tuning tests were conducted while maintaining a uniform air gap (using the mechanical clamps of the rig) between the stator poles and the rotor.

NASA Glenn researchers modified the PWM amplifiers by replacing a fixed resistor in the $\mathrm{R}-\mathrm{C}$ error amplifier compensation circuit with a 0 - to $2-\mathrm{M} \Omega$ variable resistor. A swept-sine signal was inputted to the amplifiers and the ratio of the current sensor output to the swept-sine voltage input was monitored in the frequency and phase domain. The 2-M $\Omega$ potentiometer was adjusted to optimize amplifier bandwidth while maintaining stability (see figs. 12 and 13 for the resulting transfer function plots of the coils in the bearings). It should be noted that the two coils in the thrust bearing are nearly identical and the eight coils in the radial bearings (four in each bearing) are nearly identical; hence, only two typical transfer function curves are presented: one for the thrust bearing and one for the radial bearings.

Figure 12(a) shows that the magnitude of the power amplifier gain (current out divided by voltage in) for the thrust coil is approximately flat for input excitation signals ranging up to about $2000 \mathrm{~Hz}$. The accompanying phaseshift curve (fig. 12(b)) indicates that at $1000 \mathrm{~Hz}$, the output current is phase shifted $-45^{\circ}$ relative to the input signal. For the radial bearings (fig. 13), the gain is flat to about $1000 \mathrm{~Hz}$ and the output current is phase shifted $-90^{\circ}$ relative to the input signal.

Between each amplifier and its associated bearing coil is a commercially available current sensor (fig. 14). Using the current sensor output and the four trim pots on the PWM amplifier, each amplifier was tuned to its associated coil. Direct-current offsets were eliminated and the amplifier dc gains were set to $1 \mathrm{~A} / \mathrm{V}$. A low-amplitude, $100-\mathrm{Hz}$ sine wave was inputted to the PWM and the current sensor output monitored in the time domain to verify phase, amplitude gain, offset, and noise content. After fine adjustments were completed, other input sine wave signals at various frequencies and amplitudes were checked.
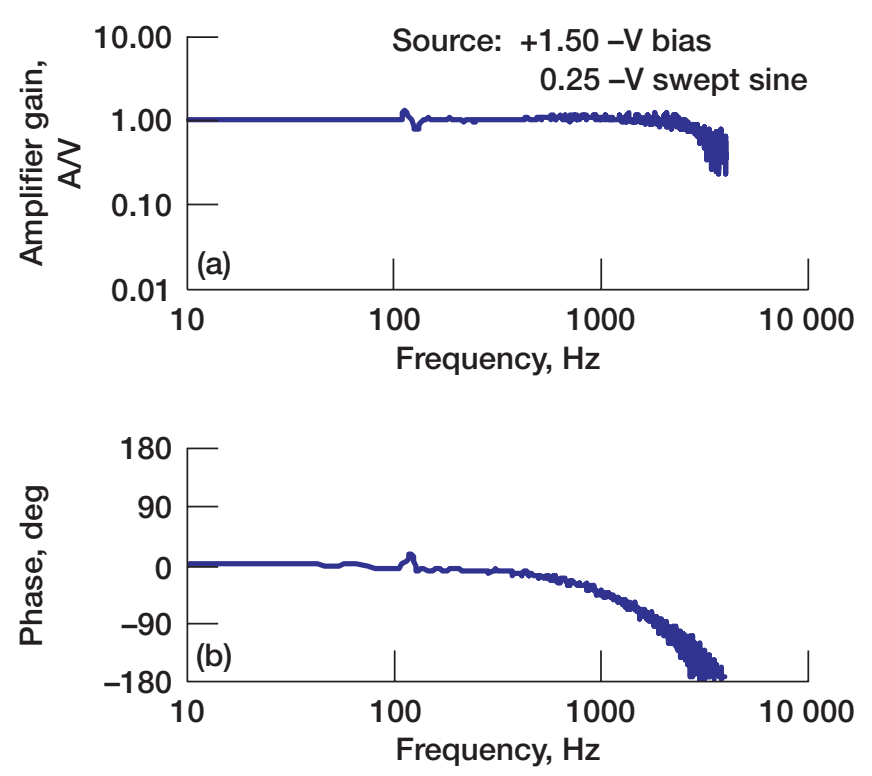

Figure 12.-Transfer function for thrust bearing. (a) Gain. (b) Phase.
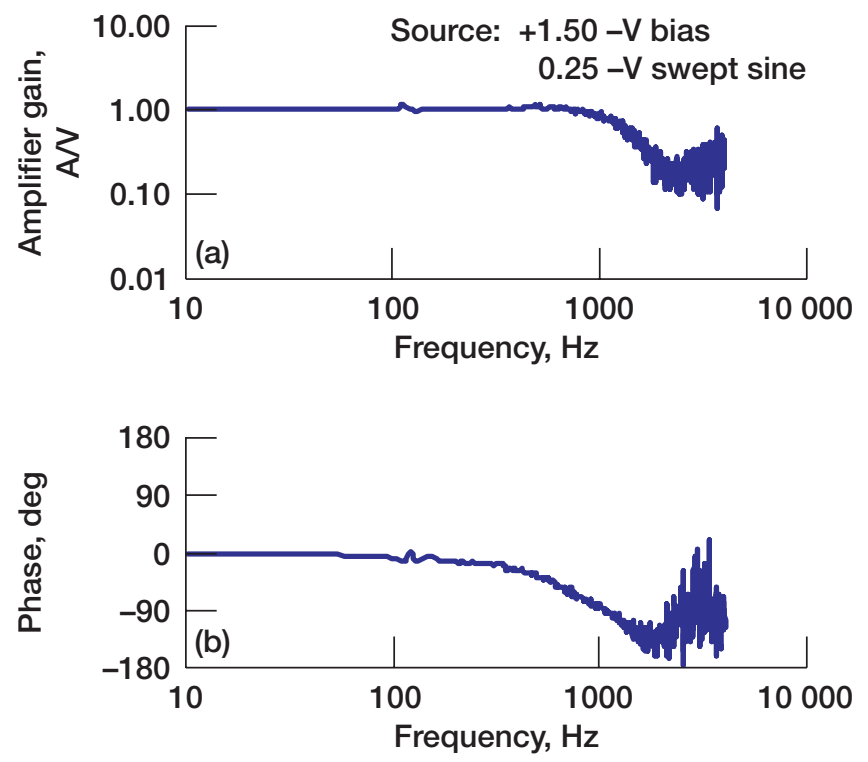

Figure 13.-Transfer function for radial bearings. (a) Gain. (b) Phase.

For the effective application of any excitation forces to the suspended rotor, the levitation of the rotor must be robust. It is therefore imperative that the stiffness-damping parameters be suitably adjusted. These parameters are discussed in the following section. 


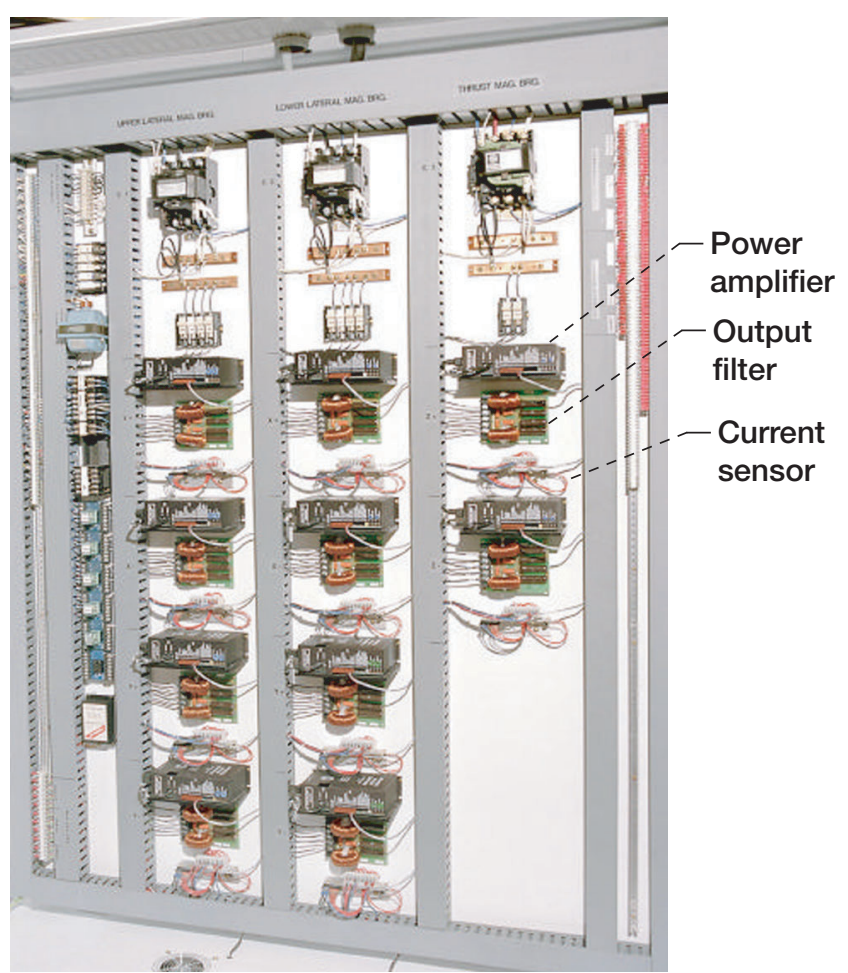

Figure 14.-Bank of power amplifiers with their associated output filters and current sensors.

\section{Stiffness-Damping-Parameter Stability} Map

Robust levitation of the rotor requires the appropriate setting of the digital (proportional-derivative) controller stiffness and damping values (ref. 6). For this report, however, the latest version of the code discussed in reference 6 was employed to obtain the nonrotating stability limit curves for the thrust, upper, and lower bearings (figs. 15(a) to (c)). It is evident from these curves that for a given stiffness value, the corresponding damping values should reside between the extreme limits defined by the stiffness-damping curve envelope. For the current rig configuration, a stiffness gain of 1.20 digital units and a damping gain of 35.0 digital units were used for the thrust bearing. The upper bearing stiffness-damping gains were 1.7 and 35.0 digital units and for the lower radial bearing, stiffness-damping gains of 1.7 and 25.0 digital units. It was observed that these values were also appropriate for rotational speeds up to $10000 \mathrm{rpm}$ (the highest speed at which the rig was tested without blades). These digital units are specific to the controller code (ref. 6 and its latest version) and are the analogs of the stiffness and damping used in classical spring mass-damper dynamics.
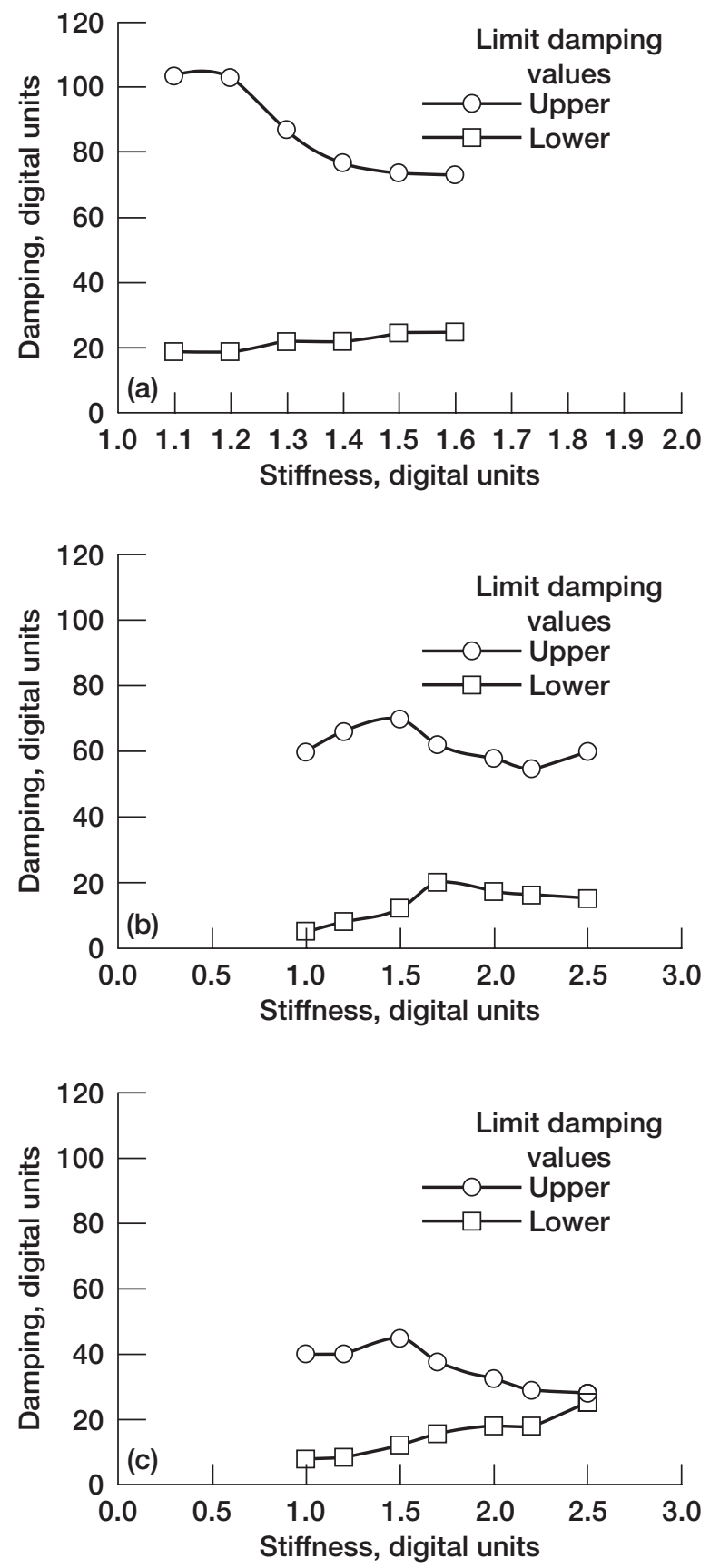

Figure 15.-Static stability limit. (a) Thrust bearing. (b) Upper bearing. (c) Lower bearing.

A number of novel features and refinements were implemented in this latest version of the controller code. These features include logic for (a) thrust bearing soft touchdown, (b) thrust plate demagnetization, (c) automatic angular sweep of the forced-excitation vector, and (d) adjustment of the tilt pivot point along the rotor. These features are discussed in detail in the following section. 


\section{New Software Features}

To avoid potential damage to the rotor and the axial backups, a soft delevitation scheme was incorporated in the controller. Figure 16 shows the controlled rampdown of the thrust plate position from the axial levitation point to the touchdown surface. This rampdown is achieved by commanding a linearly decreasing levitation center by adjusting the offset term added to the force equation signal until touchdown occurs. Figure 17 shows the current level in the upper axial magnetic bearing during this controlled rampdown. Note the slight increase in the current value from 0.5 to $1.3 \mathrm{sec}$, which indicates the control algorithm is working to overcome the increased magnetic reluctance in the upper gap as it attempts to preserve levitation during the rampdown.

Periodically, axial thrust disk remnant magnetization hinders axial relevitation using baseline controller gains. This situation usually requires the modification of the control bias in addition to the controller feedback stiffness to pull the thrust disk away from the top or bottom backup surface. To eliminate this problem, a new demagnetization scheme was implemented. In figure 17, the demagnetization current duration ranges from 1.9 to $4.0 \mathrm{sec}$. At $1.9 \mathrm{sec}$, the rotor is sitting just above the lower backup surface when the controller forces the current into an exponentially decaying cosine oscillation with a frequency of $5 \mathrm{~Hz}$ and no dc offset. This full-reversal-current signal, which decays in about $2 \mathrm{sec}$, significantly reduces the remnant field in the disk. In addition, the controller keeps track of the direction of the current in both axial stators during levitation. Upon delevitation, the controller reverses the direction of the current for the next operation. This logic helps counter any remaining remnant field not suppressed initially using the decay technique.

Another novel feature implemented in the code is the user-defined and user-initiated automatic angular sweep of the forced-excitation signal used to excite the blades. The excitation angular sweep can range from $0^{\circ}$ to $360^{\circ}$ relative to the vertical plane containing the test blades as they rotate. However, an angular sweep from $0^{\circ}$ to $180^{\circ}$ is typical. The implementation of this option was motivated by the observation of a diminution in blade response amplitude at speeds above $7500 \mathrm{rpm}$ as measured by stationary fiber optical displacement transducers. For example, the excitation phase angle at maximum blade response had shifted from the desired $90^{\circ}$ to a new value of $95^{\circ}$. The authors infer that this angular change is directly related to the phase shifts in the currents depicted in figures 12 and 13.

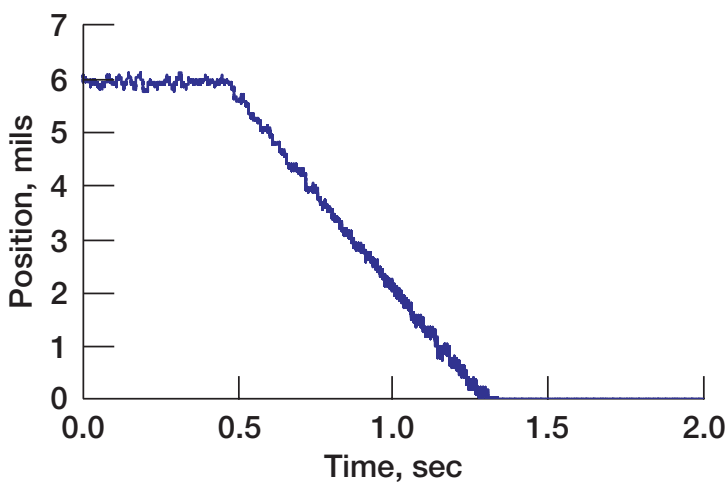

Figure 16.-Soft delevitation of Dynamic Spin Rig rotor.

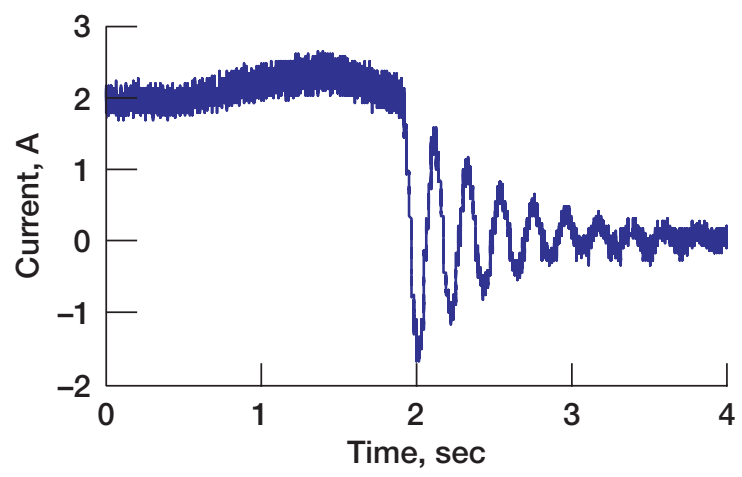

Figure 17.-Current in upper axial stator during delevitation and demagnetization.

In an actual test (at rotor speeds at or above $7500 \mathrm{rpm}$ ), an excitation angular sweep is initiated over a set time interval ( $10 \mathrm{sec}$ for example) and simultaneously the blade response (obtained with the aid of stationary fiber optical displacement transducers) is measured over the selected time interval. The angle at maximum resonance response is noted (at the desired rotor speed) and then is set for use in subsequent blade excitation and/or damping tests at that rotor speed.

For flat-plate blades oriented in a vertical plane, the ability to excite torsional modes in the blades is a desirable feature for the rig. Torsional mode is best excited by rotor tilt motion. The tilt pivot point along the rotor may be adjusted upwards or downwards through the center of the hub or disk, allowing the operator to optimize the pivot location for maximum torsional effect. At the time of this writing, this option had not been exercised for the test blades. The excitation tests were conducted in the bounce mode only, the results of which are discussed extensively in the following section. The latest version of the code is available online at https://technology.grc.nasa.gov/software. 


\section{Demonstration of Excitation Capability}

As mentioned previously, the five-axis rig represents a significant advancement in the DSR because the rotor speed is not limited to $18000 \mathrm{rpm}$ and the rig operator now has the ability to excite (at various frequencies) rotor rigid body motions (bounce and tilt) for a more effective and thorough investigation of blade excitation and damping. The rotor excitation is achieved by applying an excitation signal concurrently to the upper and lower radial bearings. At each bearing, excitation signals are applied simultaneously to the $\mathrm{x}$ - and $\mathrm{y}$-axes. This simultaneous excitation produces a resultant force vector with a magnitude and an angular orientation. The direction and amplitude of this force vector can be fixed in a nonrotating laboratory frame of reference or made to rotate with the test article by enabling the synchronous-rotating-force feature in the control code (ref. 6). A tiny mirror attached to the shaft reflects a beam of laser light once every rotation of the shaft. A sensor then converts the reflected light pulses to electrical pulses. The pulses are sent to an input channel on the A/D board and are used to trigger the synchronous-rotatingforce logic block in the code, which then synchronizes the force vector with the rotating shaft.

The excitation capability discussed above was demonstrated in the following set of experiments. In these tests, the rotor and a two-blade test article were instrumented with three Kistler accelerometers $(100 \mathrm{mV} / \mathrm{g})$ to characterize the nonrotating excitation potential of the five-axis magnetic suspension system. Figure 18 shows two of these accelerometers: one mounted to the blade and one mounted on the blade-base support structure. The third accelerometer (not shown) was mounted perpendicular to the blade row at the bottom of the rotor.

To characterize how much excitation capability exists, a determination of the amount of acceleration and displacement that can be provided at the base of the blade is appropriate. All data to follow were recorded using an HP 3665A Spectrum Analyzer in the configuration shown in figure 18. Figure 19 presents curves of blade-base acceleration versus frequency constructed from individual data points taken at predetermined frequencies. In all tests, the excitation was generated in phase by both radial magnetic bearings. The excitation orientation was perpendicular to the blade mounting plane. An acceleration value greater than $1.0 \mathrm{~g}$ appears at the rotor first-bending critical $(355 \mathrm{~Hz})$ for each of the four excitation amplitudes. Figure 20 shows the corresponding base displacements determined by dividing the acceleration by the frequency squared: $x=\left(\mathrm{g} \times 32.2 \mathrm{ft} / \mathrm{s}^{2} \times 12 \mathrm{in} . / \mathrm{ft} \times 1000 \mathrm{mil} / \mathrm{in}.\right) / \omega^{2}$.

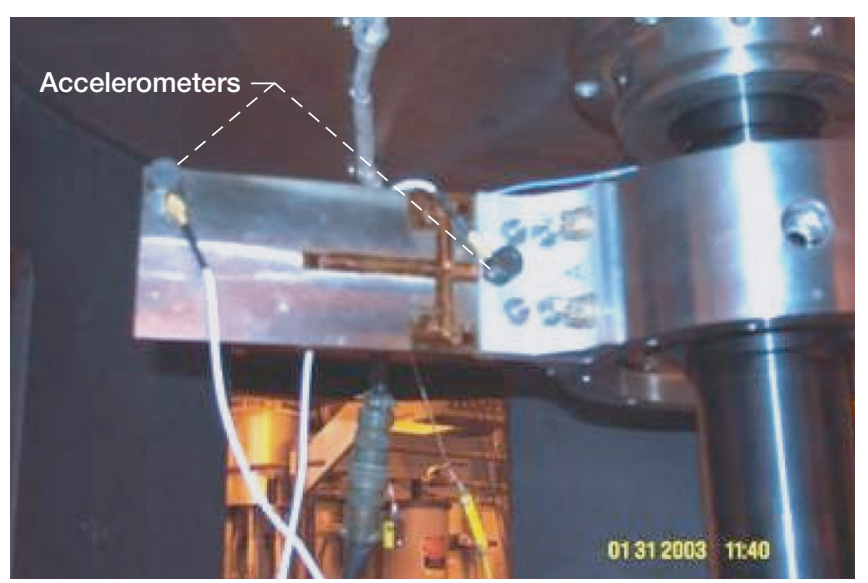

Figure 18.-Spin rig rotor assembly showing location of accelerometers on blade and blade base.

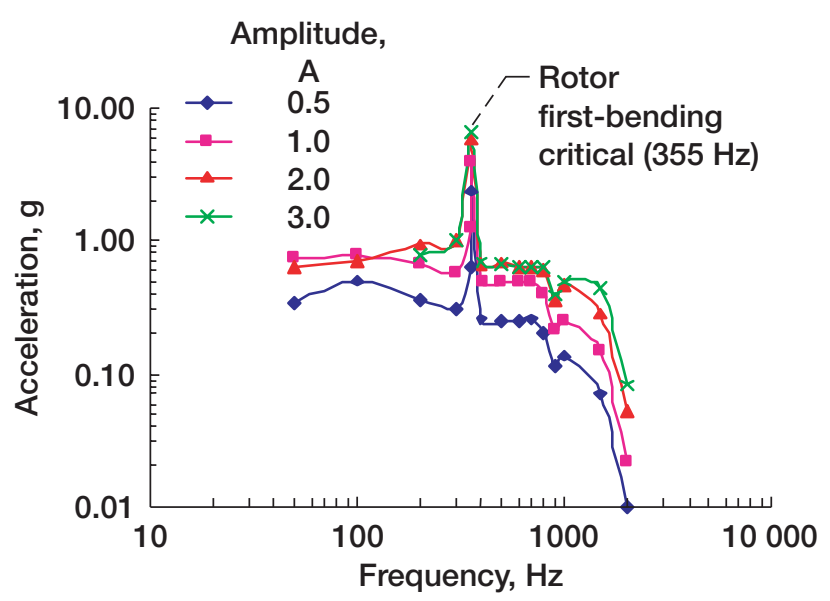

Figure 19.-Single-point, blade-base acceleration data for bounce excitation (nonrotating shaft).

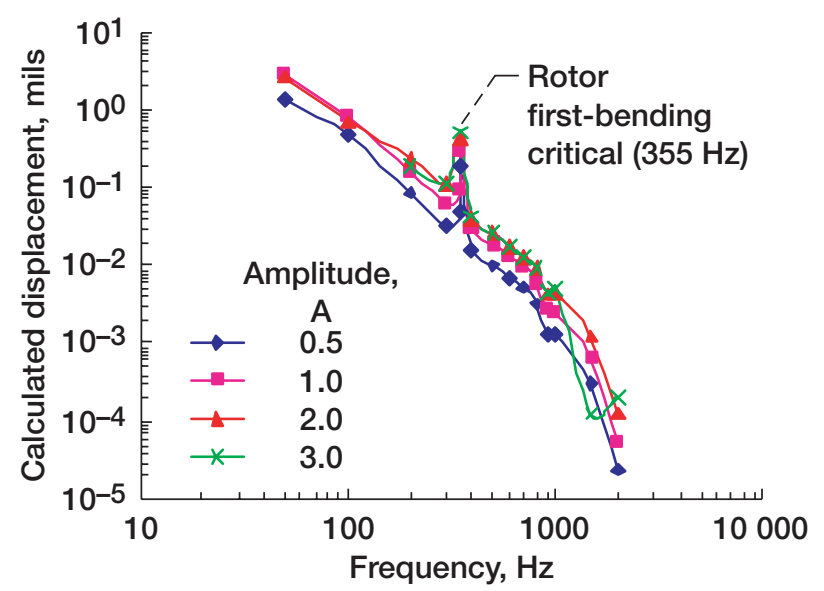

Figure 20.-Calculated blade-base displacements. 
Base acceleration data for excitation current amplitudes up to $3 \mathrm{~A}$ in figure 19 are roughly constant with respect to frequency between 50 and $1000 \mathrm{~Hz}$, and correspondingly the resulting base displacement amplitude decreases quadratically with frequency (fig. 20). The sharp rolloff after $1 \mathrm{kHz}$ is due to the combined bandwidths of the magnetic suspension system components (control computer, filters, sensors, actuators). The transfer function (the ratio of blade-base acceleration to the magnetic-bearing control current) in figures 21 and 22 provides a more thorough investigation of how the rotor responded to an excitation current amplitude of $1 \mathrm{~A}$. The data were collected by using a swept-sine excitation. Figure 21 shows the acceleration magnitude response at the blade base. It is clear that rotor response is affected by the presence of the blade(s).The perception of the authors is that these relatively thick blades are heavier and have higher resonances than most blades that will be tested. It should also be noted here that these tests were performed for one set of controller gains. These gains appear to provide the best levitation but are not necessarily the ones that will handle all dynamic spin conditions.

The peak at $144 \mathrm{~Hz}$ fortuitously matches the blade firstbending frequency measured by bench holography (table I). However, in the rig, the expectation is that this mode will be shifted and split by two effects. First, the authors expect a mistuning effect caused by the mass loading of the accelerometer that is mounted near the tip of blade A (blade B has no accelerometer). Second, even if the accelerometer were not present, we would expect two system

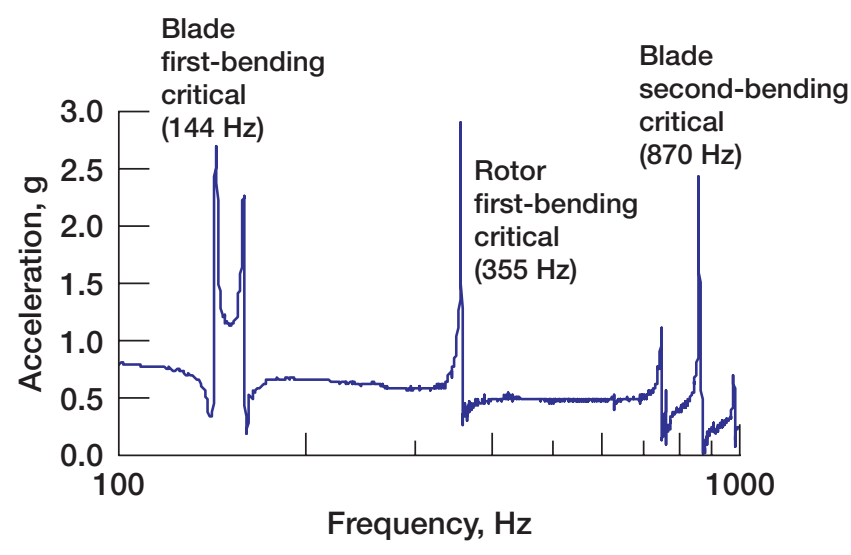

Figure 21.-Blade-base acceleration amplitude data obtained using swept-sine bounce excitation.

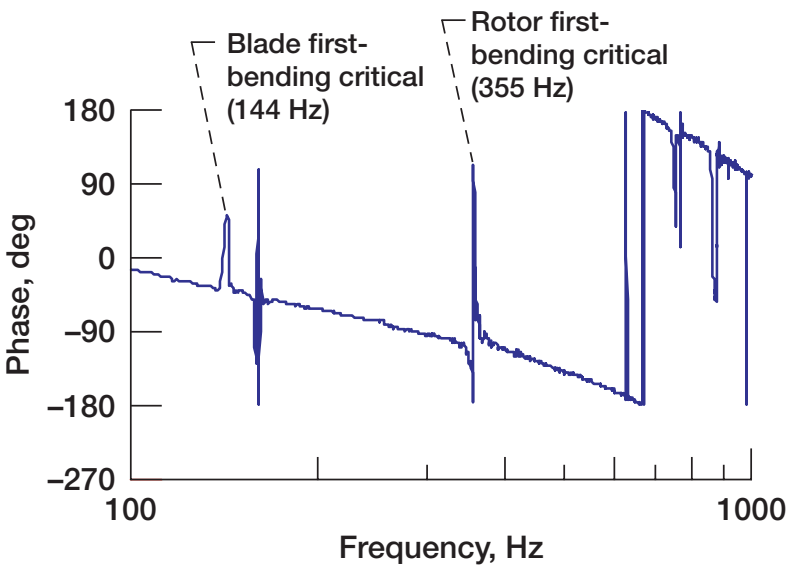

Figure 22.-Corresponding base excitation phase angle between swept-sine bounce excitation and acceleration measurement.

TABLE I.-TITANIUM TEST BLADE RESONANCES

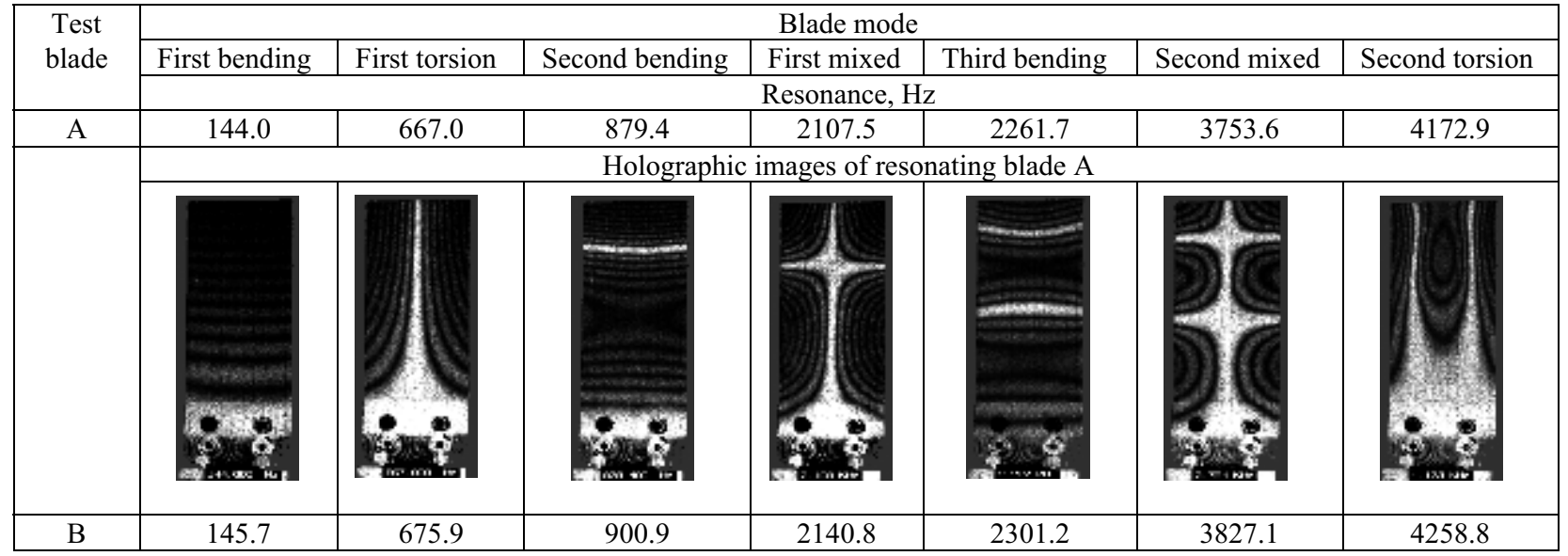




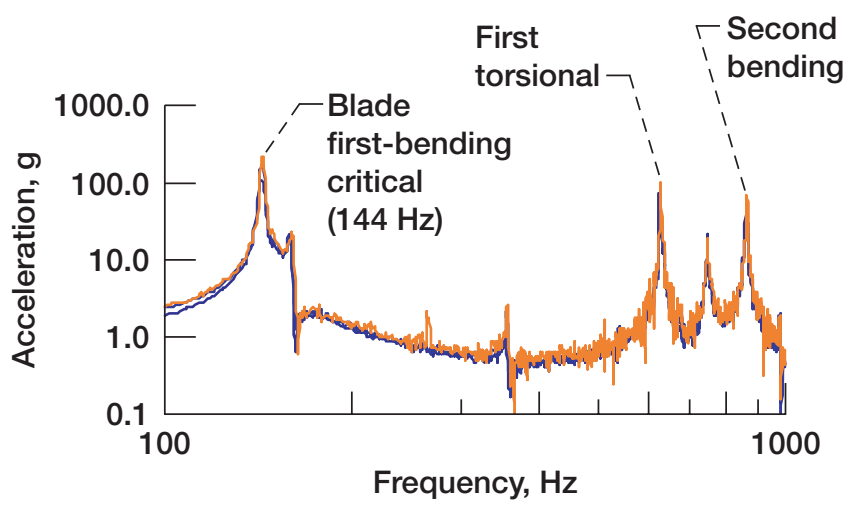

Figure 23.-Blade-tip acceleration magnitude using swept-sine excitations of $0.5,1.0$, and $2.0 \mathrm{~A}$.

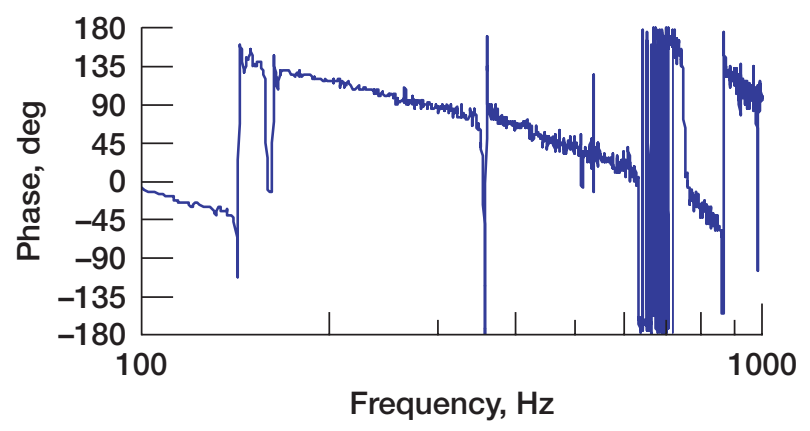

Figure 24.-Phase of swept-sine magnetic-bearing excitation to blade-tip acceleration.

modes that involve the motions of the two blades coupled with the transverse motion of the shaft and the rotation of the shaft about its axis. One mode, with the blades moving in phase, reacts against shaft translational motion. The other, with the blades moving out of phase, reacts against shaft rotational motion about its axis. The latter mode can only be excited by the magnetic bearings if there is blade mistuning. Therefore, there are potentially four modes for the mistuned system. However, only two modes are visible in figures 21 and 22. Because the base-mounted accelerometer is located on the blade centerline, it is not expected to be sensitive to first-torsional motion of the blade; hence, no peak is seen near the bench-measured first-torsion frequency $(\sim 670 \mathrm{~Hz})$. A strong peak is seen in figure 21 around $870 \mathrm{~Hz}$, not far from the bench second-bending frequency. The only rotor mode in this plot is that represented by the third peak and it does show the largest amplitude at $355 \mathrm{~Hz}$. This frequency is the rotor firstbending natural frequency as determined by impact testing and analysis. The character of the fourth and sixth peaks

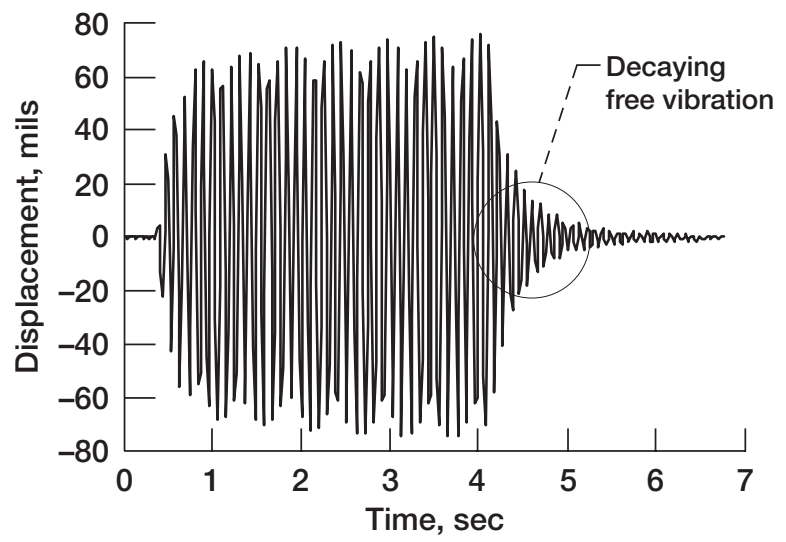

Figure 25.-Blade excitation and free-vibration decay at $3000 \mathrm{rpm}$.

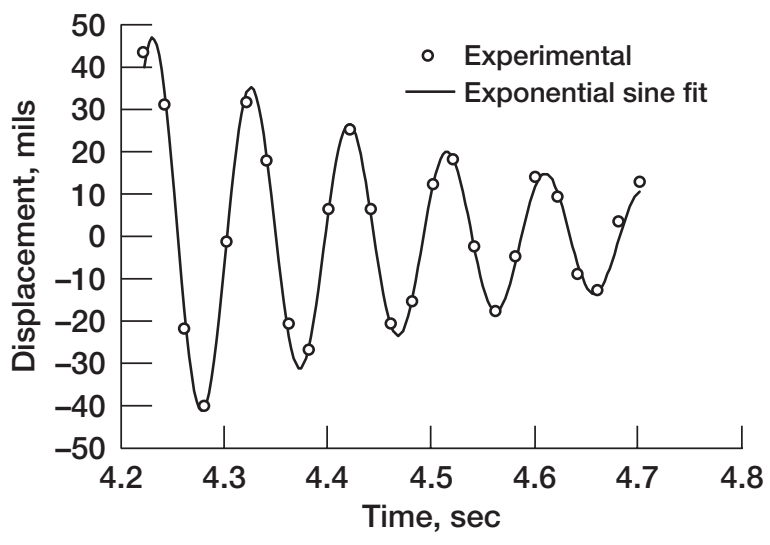

Figure 26.-Exponential sine fit to decaying free vibration shown in fig. 25.

remains undetermined. Further analysis and measurement will be required to identify positively their true nature.

Figure 22 shows the corresponding phase response from excitation to acceleration. The phase lag is substantial, confirming that excitation will have to lead the zero-speed excitation orientation with respect to the blade row by a predetermined amount. This required lead angle will be a function of rotor speed and excitation frequency and is partly determined by the data in figure 22 .

Figures 23 and 24 present the transfer function curves (ratio of blade-tip acceleration to magnetic-bearing control current) resulting from a 1-A, 0-to-peak-amplitude, sweptsine excitation perpendicular to the vertical plane that contains the blades. Tests at 0.5-, 1.0-, and 2.0-A current amplitudes indicate that tip accelerations on the order of about $100 \mathrm{~g} / \mathrm{A}$ are achievable at 0 speed at the blade first-bending critical of about $144 \mathrm{~Hz}$ and at the firsttorsional and second-bending-frequency blade modes. The 
first-torsional mode was excited and captured (albeit not using the tilt mode excitation setting) because of the offaxis placement of the accelerometer as depicted in figure 18 .

Subsequent to the nonrotating test discussed above, blade excitation at $3000 \mathrm{rpm}$ was examined. Figure 25 shows blade displacements at the first-bending-frequency mode during rotation, followed by free-vibration decay. The synchronous-rotating-force feature was engaged, thus enabling excitation to be maintained at $90^{\circ}$ relative to the blade row during rotation. These measurements were obtained with stationary fiber optical displacement transducers that sampled each blade once per revolution. Since the natural vibration frequency was significantly higher than the rotational frequency, the displacement amplitude data are aliased about half the rotational frequency. The true frequency, however, can be recovered with the use of the second transducer, which was installed $30^{\circ}$ away from the first. The frequency $(144 \mathrm{~Hz})$ was obtained from the displacement phase angles and the known separation between the two transducers. The apparent damping obtained from the least-squares fit illustrated in figure 26, therefore, must be divided by the ratio of the true natural frequency and measured aliased frequency. This ratio was 15 and yielded the value of true critical damping of 0.003 . One can observe from figure 25 that a displacement amplitude of 70 mils was achieved with this blade sample.

\section{Concluding Remarks}

The excitation test results of the unbladed and bladed rotor clearly demonstrated the usefulness of the Five-Axis,
Three-Magnetic-Bearing Dynamic Spin Rig as a versatile tool for doing detailed analyses of the vibration and damping of bladed disks. Factors contributing to this versatility and usefulness include (1) the implementation of three active magnetic bearings that fully levitate the rotor under closed-loop control, thus permitting larger rotor translation and tilt displacement and (2) the use of an enhanced control code. The code will allow an operator to (a) optimize the blade excitation angle that permits maximum resonance response from the rotating and nonrotating blades and (b) optimize the pivot location during tilt mode excitation tests to achieve maximum torsional response. Other code refinements include soft touchdown logic, which is used for gently delevitating the thrust plate onto the backup bearings, and demagnetization logic, which is used for demagnetizing the thrust plate.

A rotor first-bending-frequency mode of $355 \mathrm{~Hz}$ was discerned from the plot of acceleration versus frequency. Blade-tip excitation amplitude (at $0 \mathrm{rpm}$ ) of approximately $100 \mathrm{~g} / \mathrm{A}$ was achieved at the first-bending critical frequency mode $(\sim 144 \mathrm{~Hz})$ and at the first-torsional and second-bending-frequency blade modes. A blade-tip displacement of 70 mils was achieved at the blade firstbending-frequency mode by exciting the blades at a forced-excitation phase angle of $90^{\circ}$ relative to the vertical plane containing the blades while simultaneously rotating the shaft at $3000 \mathrm{rpm}$.

Glenn Research Center

National Aeronautics and Space Administration

Cleveland, Ohio, November 7, 2003 



\section{Appendix A \\ Magnetic Suspension Theory}

To calculate the attractive force between the ferromagnetic stator and rotor where $\mu_{r}>>1$, one has to consider first the energy $W_{a}$ extant in the air gap between the stator and rotor (ref. 8). If the field in the air gap is assumed homogeneous as represented in figure 27, the energy $W_{a}$ stored in the volume $V_{a}$, has the form

$$
W_{a}=\frac{1}{2} B_{A_{a}} H_{A_{a}} V_{a}=\frac{1}{2} B_{A_{a}} H_{A_{a}} A_{a} 2 s
$$

A change in the field energy in the air gap with respect to rotor position produces an electromagnetic force. This force is derived in equation (A2) wherein the relation $B=$ $\mu_{0} \mu_{r} H$ is used and the magnetic flux $B_{A_{a}} A_{a}$ is considered invariant for infinitesimal displacement $\mathrm{d} s$, hence,

$$
f_{a}=\frac{\mathrm{d} W_{a}}{\mathrm{~d} s}=B_{A_{a}} H_{A_{a}} A_{a}=\frac{B_{A_{a}}^{2} A_{a}}{\mu_{0}}
$$

Inserting equation(B6) in equation (A2) produces the force equation:

$$
f_{a}=\mu_{0} A_{a}\left(\frac{n i}{2 s}\right)^{2}=\frac{1}{4} \mu_{0} n^{2} A_{a} \frac{i^{2}}{s^{2}}=z \frac{i^{2}}{s^{2}}
$$

where $z=\left(\mu_{0} n^{2} A_{a}\right) / 4$.

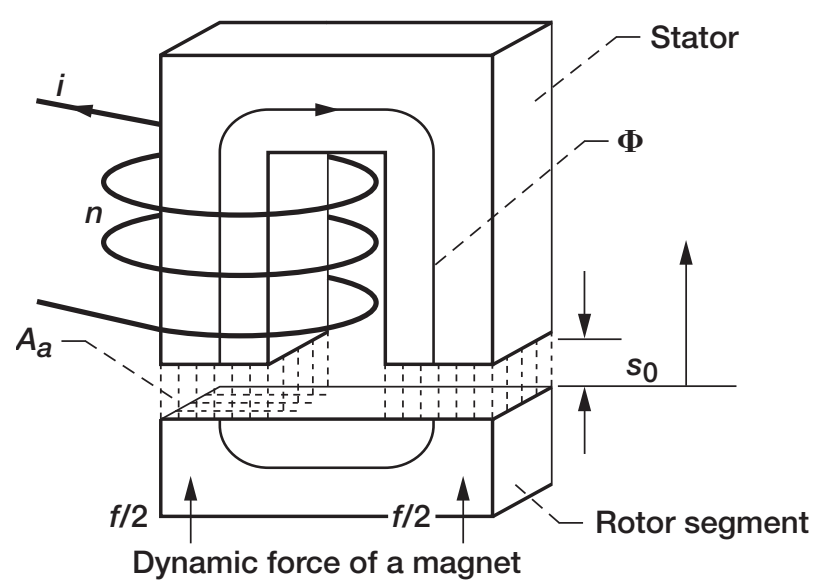

Figure 27.-Rotor-stator segment.
It is evident from equation (A3) that the magnetic force has a quadratic dependence on current and an inverse quadratic dependence on the air gap. The net controlling force (due to an opposing pair of identical electromagnets) acting on a rotor can thus be represented as (ref. 5)

$$
F=z\left(\frac{i_{1}^{2}}{s_{1}^{2}}-\frac{i_{2}^{2}}{s_{2}^{2}}\right)
$$

where $i_{1}$ and $i_{2}$ are the current in the opposing coils; $s_{1}$ and $s_{2}$ are the gap distances between the rotor and each opposing pole face.

The squared terms in equation (A4) are undesirable from a control standpoint and are eliminated by using a linearizing technique that incorporates a bias current and a control current. By replacing $i_{1}$ and $i_{2}$ in equation (A4) with $\left(i_{b}+i_{c}\right)$ and $\left(i_{b}-i_{c}\right)$, respectively, and $s_{1}$ and $s_{2}$ with $\left(s_{0}-s_{d e}\right)$ and $\left(s_{0}+s_{d e}\right)$, respectively, the force exerted by the two actuators takes the form

$$
F=z\left[\frac{\left(i_{b}+i_{c}\right)^{2}}{\left(s_{0}-s_{d e}\right)^{2}}-\frac{\left(i_{b}-i_{c}\right)^{2}}{\left(s_{0}+s_{d e}\right)^{2}}\right]
$$

where $i_{b}$ and $i_{c}$ are the bias current and the control current, respectively; $s_{0}$ is the nominal gap distance, and $s_{d e}$ is the deviation from the nominal value. After making the appropriate algebraic manipulation and taking the requisite partial derivative, the linearized force $F_{l}$, current, and position are shown to have the approximate relationship

$$
F_{l}=\boldsymbol{K}_{s} s_{d e}+\boldsymbol{K}_{i} i_{c}
$$

for $i_{c}<<i_{b}$ and $s_{d e}<<s_{0}$ and where $\boldsymbol{z}_{s}$ is the position stiffness and $z_{i}$ is the current stiffness. In the case of proportional-derivative feedback control when an excitation signal is used, $i_{c}$ is replaced with $-\left(K_{p} s_{d e}+K_{d} \dot{s}_{d e}\right)+i_{e x}$ where $K_{p}$ and $K_{d}$ are the proportional control gain and derivative control gain, respectively, and $i_{e x}$ is the current used to produce a forced excitation of the shaft. The equation of motion for the shaft displacement $s_{d e}$ is 


$$
F_{e x}=m_{e q} \ddot{s}_{d e}+\boldsymbol{K}_{i} K_{d} \dot{s}_{d e}+\left(\boldsymbol{ス}_{i} K_{p}-\boldsymbol{K}_{s}\right) s_{d e}
$$

where $m_{e q}$ is the rigid rotor equivalent lumped mass and $F_{e x}$ $=z_{i} i_{e x}$. Further algebraic simplification produces an expression of the form

$$
F_{e x}=m_{e q} \ddot{s}_{d e}+c_{e q} \dot{s}_{d e}+k_{e q} s_{d e}
$$

Therefore,

$$
m_{e q} \ddot{s}_{d e}=-k_{e q} s_{d e}-c_{e q} \dot{s}_{d e}+F_{e x}
$$

where $c_{e q}=z_{i} K_{d}$ and $k_{e q}=z_{i} K_{p}-z_{s}$.

Equation (A9) is at the heart of magnetic-bearing control and is the crux of the five-axis-rig control code (ref. 6 and its latest version). 


\section{Appendix B \\ Magnetic Circuit}

In the case of a magnetic bearing where iron is used in the stator and rotor (ref. 8), electromagnets cause a flux $\Phi$ to circulate in a magnetic loop (see fig. 28 for an approximation to the flux path through the stator and rotor). One assumes that the flux is entirely confined to the iron (no flux leakage) except in the air gap. Further assumed is that the flux runs entirely within the magnetic loop in which the iron cross section $A_{f e}$ is constant along the entire loop and is equal to the cross section $A_{a}$ in the air gap. Thus, the relation can be stated as

$$
\Phi=B_{A_{f e}} A_{f e}=B_{A_{a}} A_{a}
$$

where $A_{f e}=A_{a}$ and

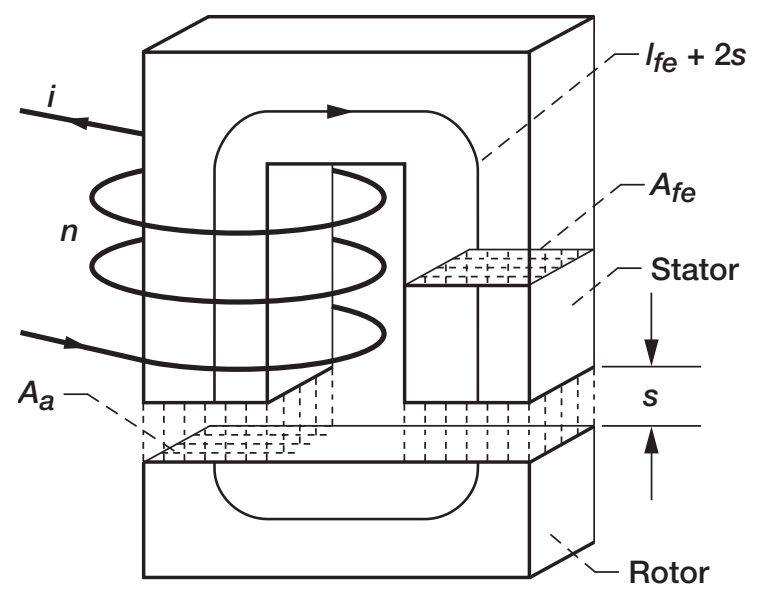

Figure 28.-Magnetic circuit.

$$
B_{A_{f e}}=B_{A_{a}}=B
$$

For a homogeneous field within the magnetic loop, consider the mean length $l_{f e}$ of the magnetic displacement and an air gap of length $2 s$. If the iron has constant permeability, the equation for the magnetic circuit depicted in figure 28 can be written as

$$
\oint H \mathrm{~d} s=l_{f e} H_{A_{f e}}+2 s H_{A_{a}}=n i
$$

The term $n i$ in equation (B3) is usually referred to as the "magnetomotive force" ( $\mathrm{mmf}$ ). It is evident from equation (B2) that the flux density $B$ in the iron and the air gap is identical. The field intensities $H_{A_{f e}}$ and $H_{A_{a}}$ in equation (B3) can be replaced by using the relation $B=\mu_{0} \mu_{r} H$; hence,

$$
l_{f e} \frac{B}{\mu_{0} \mu_{r}}+2 s \frac{B}{\mu_{0}}=n i
$$

Explicitly solving for $B$ yields the expression

$$
B=\mu_{0} \frac{n i}{\left(\frac{l_{f e}}{\mu_{r}}+2 s\right)}
$$

For iron in which $\mu_{r} \gg 1$, equation (B5) simplifies to

$$
B=\mu_{0} \frac{n i}{2 s}
$$





\section{References}

1. Szasz, Gyorgy; Flowers, George T.; and Hartfield, Roy J.: Hub Based Vibration Control of Multiple Rotating Airfoils. AIAA Paper 98-3312, 1998.

2. Chang, Jim C.I.: An Integrated Research Approach to Attack Engine HCF Problem. Proceedings of the ASME Aerospace Division International Mechanical Engineering Congress and Exposition, ASME, New York, NY, 1996, pp. 313-320.

3. Meher-Homji, Cyrus B.: Blading Vibration and Failures in Gas Turbines Part A: Blading Dynamics \& the Operating Environment. ASME Paper 95-GT-418, 1995.

4. Brown, G.V., et al.: Lewis Research Center Spin Rig and Its Use in Vibration Analysis of Rotating Systems. NASA TP-2304, 1984.
5. Johnson, Dexter; Brown, Gerald V.; and Mehmed, Oral: A Magnetic Suspension and Excitation System for Spin Vibration Testing of Turbomachinery Blades. NASA/TM-1998-206976 (AIAA Paper 98-1851), 1998.

6. Morrison, Carlos R.: A Comprehensive C++ Controller for a Magnetically Supported Vertical Rotor; 1.0. NASA/TM-2001-210701,2001.

7. Choi, Benjamin, et al.: A Comparison Study of Magnetic Bearing Controllers for a Fully Suspended Dynamic Spin Rig. ISMB-8Paper-0160, 2002.

8. Schweitzer, Gerhard; Bleuler, Hannes; and Traxler, Alfons: Active Magnetic Bearings: Basics, Properties and Applications of Active Magnetic Bearings. Vdf Hochschulverlag, Zurich, 1994. 
Public reporting burden for this collection of information is estimated to average 1 hour per response, including the time for reviewing instructions, searching existing data sources, gathering and maintaining the data needed, and completing and reviewing the collection of information. Send comments regarding this burden estimate or any other aspect of this collection of information, including suggestions for reducing this burden, to Washington Headquarters Services, Directorate for Information Operations and Reports, 1215 Jefferson Davis Highway, Suite 1204, Arlington, VA 22202-4302, and to the Office of Management and Budget, Paperwork Reduction Project (0704-0188), Washington, DC 20503.

1. AGENCY USE ONLY (Leave blank) 2. REPORT DATE 3. REPORT TYPE AND DATES COVERED

\section{TITLE AND SUBTITLE} January 2004

Technical Paper

Fully Suspended, Five-Axis, Three-Magnetic-Bearing Dynamic Spin Rig With Forced Excitation

6. AUTHOR(S)

WBS-22-708-28-14

Carlos R. Morrison, Andrew Provenza, Anatole Kurkov, Gerald Montague, Kirsten Duffy, Oral Mehmed, Dexter Johnson, and Ralph Jansen

5. FUNDING NUMBERS

PERFORMING ORGANIZATION NAME(S) AND ADDRESS(ES)

National Aeronautics and Space Administration

John H. Glenn Research Center at Lewis Field

Cleveland, Ohio 44135-3191

8. PERFORMING ORGANIZATION REPORT NUMBER

E-14196

\section{SPONSORING/MONITORING AGENCY NAME(S) AND ADDRESS(ES)}

10. SPONSORING/MONITORING AGENCY REPORT NUMBER

National Aeronautics and Space Administration

Washington, DC 20546-0001

NASA TP-2004-212694

\section{SUPPLEMENTARY NOTES}

Carlos R. Morrison, Andrew Provenza, Anatole Kurkov, Oral Mehmed, and Dexter Johnson, NASA Glenn Research Center; Gerald Montague, U.S. Army Research Laboratory, NASA Glenn Research Center; and Kirsten Duffy and Ralph Jansen, University of Toledo, Toledo, Ohio 43606. Responsible person, Carlos Morrison, organization code 5930, 216-433-8447.

12a. DISTRIBUTION/AVAILABILITY STATEMENT 12b. DISTRIBUTION CODE

Unclassified - Unlimited

Subject Categories: 05, 07, and 31

Distribution: Standard

Available electronically at http://gltrs.grc.nasa.gov

This publication is available from the NASA Center for AeroSpace Information, 301-621-0390.

\section{ABSTRACT (Maximum 200 words)}

The Five-Axis, Three-Magnetic-Bearing Dynamic Spin Rig, a significant advancement in the Dynamic Spin Rig (DSR), is used to perform vibration tests of turbomachinery blades and components under rotating and nonrotating conditions in a vacuum. The rig has as its critical components three magnetic bearings: two heteropolar radial active magnetic bearings and a magnetic thrust bearing. The bearing configuration allows full vertical rotor magnetic suspension along with a feed-forward control feature, which will enable the excitation of various natural blade modes in bladed disk test articles. The theoretical, mechanical, electrical, and electronic aspects of the rig are discussed. Also presented are the forced-excitation results of a fully levitated, rotating and nonrotating, unbladed rotor and a fully levitated, rotating and nonrotating, bladed rotor in which a pair of blades was arranged $180^{\circ}$ apart from each other. These tests include the "bounce" mode excitation of the rotor in which the rotor was excited at the blade natural frequency of $144 \mathrm{~Hz}$. The rotor natural mode frequency of $355 \mathrm{~Hz}$ was discerned from the plot of acceleration versus frequency. For nonrotating blades, a blade-tip excitation amplitude of approximately $100 \mathrm{~g} / \mathrm{A}$ was achieved at the first-bending critical $(\sim 144 \mathrm{~Hz})$ and at the first-torsional and second-bending blade modes. A blade-tip displacement of 70 mils was achieved at the first-bending critical by exciting the blades at a forced-excitation phase angle of $90^{\circ}$ relative to the vertical plane containing the blades while simultaneously rotating the shaft at $3000 \mathrm{rpm}$.

\section{SUBJECT TERMS}

15. NUMBER OF PAGES

Magnetic bearing; Thrust bearing; Active magnetic bearing; Five-axis magnetic bearing; Fully suspended rotor

\begin{tabular}{|c|c|c|}
\hline $\begin{array}{c}\text { 17. SECURITY CLASSIFICATION } \\
\text { OF REPORT } \\
\text { Unclassified }\end{array}$ & $\begin{array}{c}\text { 18. SECURITY CLASSIFICATION } \\
\text { OF THIS PAGE } \\
\text { Unclassified }\end{array}$ & $\begin{array}{c}\text { 19. SECURITY CLASSIFICATION } \\
\text { OF ABSTRACT } \\
\text { Unclassified }\end{array}$ \\
\hline
\end{tabular}

NSN 7540-01-280-5500

\begin{tabular}{|l|}
\hline 16. PRICE CODE \\
20. LIMITATION OF ABSTRACT \\
\hline
\end{tabular}

Standard Form 298 (Rev. 2-89)

Prescribed by ANSI Std. Z39-18 298-102 